EPIDEMIOLOGY

\title{
Herpes simplex virus 2 and syphilis among young drug users in Baltimore, Maryland
}

\author{
S S Plitt, S G Sherman, S A Strathdee, T E Taha
}

Sex Transm Infect 2005;81:248-253. doi: 10.1136/sti.2004.011544

See end of article for authors' affiliations

.....................

Correspondence to:

Susan G Sherman, $615 \mathrm{~N}$

Wolfe Street, E6543,

Department of

Epidemiology, Johns

Hopkins Bloomberg School

of Public Health, Baltimore,

MD 21205, USA;

ssherman@jhsph.edu

Accepted for publication 18 August 2004

\begin{abstract}
Objectives: To examine the sex specific seroprevalence and correlates of herpes simplex virus 2 (HSV-2) and syphilis among a cohort of young drug users.

Methods: Drug users aged 15-30 years old who used heroin, cocaine, or crack were recruited between October 1999 and August 2002. Baseline interviews gathered information on sociodemographics, drug use and sexual behaviours. Serum was tested at baseline for HSV-2 and syphilis seroreactivity. For each sexually transmitted infection (STI), infected and non-infected participants were stratified by sex and compared using $\chi^{2}$, Mann-Whitney tests, and logistic regression.

Results: Of the 543 participants recruited, $42.4 \%$ were female and $39.3 \%$ were African-American. The seroprevalence of STls among females and males, respectively, were HSV-2: $58.7 \%$ and $22.0 \%$; syphilis: $4.3 \%$ and $0.3 \%$. In multivariate models, older age, African-American race, having over 30 lifetime sex partners, current HIV infection and previous incarceration were independently associated with HSV-2 infection among males. For females, older age, African-American race, sex trade, and daily heroin use were independently associated with HSV-2. For females, only a self reported previous syphilis diagnosis was associated with current syphilis seroreactivity in multivariate analyses.

Conclusions: Examination of this cohort revealed a particularly high seroprevalence of HSV-2 and syphilis, especially among female drug users. Few infected participants had been previously diagnosed with these infections.
\end{abstract}

$\mathrm{U}$ lcerative sexually transmitted infections (STIs) such as herpes simplex virus type-2 (HSV-2) and syphilis have been associated with increased sexual transmission and acquisition of HIV. ${ }^{1-3}$ Ulcerative STIs increase HIV susceptibility by disrupting mucosal integrity to create a portal for viral entry and inducing the proliferation and activation of HIV susceptible cells (for example, lymphocytes, macrophages). ${ }^{4}$ HIV shedding has been shown to be higher in the presence of STI co-infection and, in the case of ulcerative STIs, HIV has been detected in ulcer exudates and bleeding of ulcers during sex allows for easier viral transmission. ${ }^{35} \mathrm{~A}$ recent literature review concluded that ulcerative STIs increase HIV susceptibility fourfold among males and threefold among females. HIV infectiousness increases by twofold in the presence of STIs. ${ }^{1}$

Drug using populations are at a high risk for acquiring STIs as a result of factors such as high risk sexual partners and increased levels of high risk sexual behaviours associated with stimulants such as crack and cocaine. ${ }^{67}$ These risks are often escalated among women because of the biological efficacy of STI transmission and the elevated prevalence of such behaviours, such as the exchange of sex for drugs or money. ${ }^{8}$

The consequences of STI/HIV co-infections are important among drug using populations as members of these populations are at higher risk than members of the general population of being HIV infected or having an HIV positive sex partner. However, few population based studies have measured STIs among drug using populations. The objective of this study was to examine the seroprevalence and correlates of ulcerative STIs (that is, HSV-2 and syphilis) among a community based cohort of young drug users, both injecting drug users (IDUs) and non-injecting drug users (NIDUs).

\section{METHODS}

\section{Study population}

Young drug users were recruited into the Risk Evaluation and Assessment of Community Health III (REACH III) cohort between October 1999 and August 2002. REACH III aimed to examine factors associated with injection and non-injection drug use, and infectious diseases among recently initiated young drug users. Eligibility criteria for all participants were (1) aged 15-30 years old; and (2) having initiated injection or non-injection use of heroin, crack, and/or cocaine within the previous 5 years. In addition, NIDUs were eligible if they reported using either heroin, crack and/or cocaine 2 days in the previous week and IDUs were eligible if they had injected at least once in the month before study entry. Injection status was verified by the presence of injection stigmas and by a series of injection drug related questions.

\section{Recruitment}

Targeted sampling methods ${ }^{10}$ were used to recruit potential participants. Recruitment areas were identified though ethnographic observations and previous research with this target population. ${ }^{11}$ Experienced street outreach workers approached people on the street in targeted neighbourhoods, attended community meetings, and posted study flyers. In addition to the study clinic, a van was used as a mobile study centre. This study van would regularly park in targeted neighbourhoods to recruit and screen potential participants.

\footnotetext{
Abbreviations: ELISA, enzyme linked immunosorbent assay; HSV, herpes simplex virus; IDUs, injecting drug users; NIDUs, non-injecting drug users; REACH III, Risk Evaluation and Assessment of Community Health III; RPR, rapid plasma reagin; STIs, sexually transmitted infections; TPHA, Treponema pallidum haemagglutinin assay
} 


\begin{tabular}{|c|c|c|}
\hline & $\begin{array}{l}\text { Females } \\
(\mathrm{n}=230) \ddagger\end{array}$ & $\begin{array}{l}\text { Males } \\
(\mathrm{n}=313) \ddagger\end{array}$ \\
\hline & $\%(n) \dagger$ & $\%(n) \dagger$ \\
\hline Age (interquartile range) & $25(21-28)$ & $24(21-27)$ \\
\hline \multicolumn{3}{|l|}{ Race: } \\
\hline White & $51.6(118)$ & $63.9(200)^{* * *}$ \\
\hline African-American & 48.5 (11) & $32.6(102)$ \\
\hline Other & 0 & $3.5(11)$ \\
\hline Homeless & $16.1(36)$ & $18.7(57)$ \\
\hline Injection drug user & $69.1(159)$ & 75.7 (237) \\
\hline Daily marijuana use§ & $13.0(29)$ & $14.9(46)$ \\
\hline Daily crack use§ & $9.6(22)$ & $2.9(9)^{* * *}$ \\
\hline Daily cocaine use§ & $14.9(34)$ & $14.1(44)$ \\
\hline Daily heroin use§ & 72.1 (165) & $74.6(232)$ \\
\hline \multicolumn{3}{|l|}{ Sex behaviours } \\
\hline Lifetime partners (range) & $8(5-20)$ & $15(8,30)^{* * *}$ \\
\hline Sex trade§ & $25.6(58)$ & $2.9(9)^{\star \star \star *}$ \\
\hline$>2$ Sex partners in the last 6 months & $33.3(76)$ & $23.5(73)^{\star}$ \\
\hline Current HIV infection & $6.5(15)$ & $2.9(9)^{*}$ \\
\hline \multicolumn{3}{|l|}{ Always use condom with§థ: } \\
\hline Steady partner & $17.8(32)$ & $14.9(34)$ \\
\hline Casual partner & $52.2(24)$ & $40.2(37)$ \\
\hline Sex trade partner & $64.4(29)$ & $55.6(5)$ \\
\hline \multicolumn{3}{|l|}{ Steady sex partnerई: } \\
\hline Snorts heroin & $45.3(86)$ & $27.0(63)^{\star \star \star}$ \\
\hline Smokes crack & $33.0(63)$ & $17.6(41)^{* * *}$ \\
\hline Injected drugs & $38.2(73)$ & $28.3(66)^{*}$ \\
\hline \multicolumn{3}{|c|}{$\begin{array}{l}{ }^{*}<0.05^{* *}<0.01{ }^{* * *}<0.001 \text {. } \\
\dagger \text { Except for continuous variables which are expressed as median and IQR. } \\
\text { †Denominator may vary from column totals due to missing data, refusals to answer specific questions or skip } \\
\text { patterns. } \\
\text { \$Refer to the previous } 6 \text { months. } \\
\text { • Refers to vaginal sex only. }\end{array}$} \\
\hline
\end{tabular}

\section{Data collection}

All eligible participants were invited to join the study and sign a written informed consent. Owing to the sensitive nature of both the study population and research topic, participants between the ages of $15-18$ years $(n=19)$ were considered emancipated minors and therefore were able to provide consent for their participation. Participants underwent an interviewer administered baseline survey and venepuncture, accompanied by pretest counselling. Participants were compensated \$20 for the completion of the baseline assessment. Participants returned after their baseline visit for test results, post-test counselling, and $\$ 10$ compensation. Data were collected at baseline as well as at the 6 and 12 month follow up. The current analysis was restricted to data collected at baseline. If participants tested positive for HIV or syphilis, a referral for further medical evaluation was provided. HSV-2 serology was conducted in December 2002 for the purpose of this research project and, as described in initial consent procedure, these post hoc test results were not reported back to the participant. The study was approved by the committee on human research at the Johns Hopkins Bloomberg School of Public Health. A certificate of confidentiality was obtained.

\section{Laboratory data}

At the baseline visit, serum was collected and tested for HIV using an enzyme linked immunosorbent assay (ELISA) (Biomerieux Vironostika (Vironos), Durham, NC, USA), followed by confirmation of reactive samples using western blot (Bio-Rad, Redman, Washington). In addition, initial testing for syphilis was done by screening all samples with the rapid plasma reagin (RPR) test (Macro-Vue, Becton Dickenson, Cockeysville, MD, USA). All samples testing positive by RPR had confirmatory testing using Treponema pallidum haemagglutinin assay (TPHA) (Fujirebio,
Wilmington, DE, USA). Samples that were reactive on both tests indicate recent or untreated infection. During primary syphilis the sensitivity of RPR and TPHA, respectively, is approximately $86 \%$ and $76 \%$, while both tests are $100 \%$ sensitive in secondary syphilis. False negative cases can occur during early primary syphilis as seroconversion may occur up to 4 weeks after the appearance of the primary lesions. ${ }^{12}$

Stored baseline serum was tested for serological markers of HSV-2 using the HerpeSelect HSV-2 type specific ELISA (Focus Diagnostics, Cypress, CA, USA), which tests for the presence of HSV-2 antibodies against recombinant gG2 antigen. Reactive tests are thus indicative of current infection. This particular ELISA has been shown to have a high sensitivity and specificity (96.1-100\%) in studies conducted among populations of varying prevalence. The type specificity of this ELISA is also very high (96.5\% relative to western blot) (Focus Diagnostics, Cypress, CA, USA).

\section{Survey instrument}

Baseline questionnaires were administered to participants by experienced, trained interviewers, certified in HIV pretest and post-test counselling. The questionnaire ascertained a range of sociodemographic information and sexual and drug use behaviours. Examined sexual behaviours included age at first intercourse; history of STIs; number of lifetime sexual partners; history of sex trade involvement; condom use in the 6 months before being surveyed; frequency and type of sex in the past 6 months; and self reported drug and sex history of partners in the past 6 months. The examination of drug use behaviours included the types and frequency of drugs used in the past 6 months. A steady sex partner was defined as someone with whom the participant had a sexual relationship for more than 3 months, not including sex trade clients. A casual sex partner was defined as someone with whom the participant had a sexual relationship for less than 
Table 2 Univariate analyses of HSV-2 seroprevalence of REACH III cohort by sex $\dagger$

\begin{tabular}{|c|c|c|c|c|c|c|}
\hline & \multicolumn{3}{|c|}{ Females $(n=230)$} & \multicolumn{3}{|c|}{ Males $(n=313)$} \\
\hline & No & $\%$ positive $(n) t \dagger \S$ & Crude OR $(95 \% \mathrm{Cl})$ & No & $\%$ positive $(\mathbf{n}) t \dagger \S$ & Crude OR (95\% Cl) \\
\hline \multicolumn{7}{|l|}{ Median age } \\
\hline Among positives & - & $26(23-28)^{\star \star *}$ & $1.2(1.1$ to 1.3$) \neq \ddagger$ & - & $26(23-28)^{* * *}$ & $1.2(1.1$ to 1.3$) \neq \ddagger$ \\
\hline Among negatives & - & $22(19-26)$ & & - & $24(20-27)$ & \\
\hline \multicolumn{7}{|l|}{$\begin{array}{l}\text { Among negailves } \\
\text { Race }\end{array}$} \\
\hline African-American & 111 & $78.4(87)^{\star * \star}$ & $5.5(3.1$ to 9.8$)$ & 103 & $35.3(36)^{\star * *}$ & $3.1(1.8$ to 5.4$)$ \\
\hline Other & 0 & - & - & 11 & $27.3(3)$ & $2.1(0.5$ to 8.5$)$ \\
\hline White & 118 & $39.8(47)$ & 1.0 & 195 & $15.0(30)$ & 1.0 \\
\hline \multicolumn{7}{|l|}{ Injection drug user } \\
\hline Yes & 159 & $58.5(93)$ & $1.0(0.6$ to 1.7$)$ & 237 & $21.9(52)$ & $1.0(0.5$ to 1.8$)$ \\
\hline No & 71 & $59.2(42)$ & & 76 & $22.4(17)$ & 1.0 \\
\hline \multicolumn{7}{|l|}{ Regular employment } \\
\hline Yes & 65 & $4.6(3)^{*}$ & $0.5(0.3$ to 0.9$)$ & 178 & $18.5(33)$ & $0.6(0.4$ to 1.1$)$ \\
\hline No & 164 & $64.0(105)$ & & 135 & $26.7(36)$ & 1.0 \\
\hline \multicolumn{7}{|c|}{ Number of lifetime opposite sex partners } \\
\hline$<10$ & 114 & $52.6(60)$ & 1.0 & 84 & $30.8(33)^{\star *}$ & 1.0 \\
\hline $10-30$ & 64 & $57.8(37)$ & $1.2(0.7$ to 2.3$)$ & 106 & $18.9(20)$ & $1.5(0.7$ to 3.4$)$ \\
\hline $30+$ & 36 & $75.0(27)$ & $2.7(1.2$ to 6.3$)$ & 107 & 13.1 (11) & $3.0(1.4$ to 6.3$)$ \\
\hline \multicolumn{7}{|c|}{ Same sex relationship ever } \\
\hline Yes & 59 & $64.4(38)$ & $1.4(0.8$ to 2.6$)$ & 10 & $50.0(5)^{*}$ & $3.7(1.0$ to 13.2$)$ \\
\hline No & 170 & $56.5(96)$ & 1.0 & 302 & $21.2(64)$ & 1.0 \\
\hline \multicolumn{7}{|l|}{ Traded sex } \\
\hline Yes & 59 & $81.0(47)^{\star *}$ & $3.9(1.9$ to 8.1$)$ & 9 & $33.3(3)$ & $1.7(0.4$ to 7.3$)$ \\
\hline No & 169 & $52.1(88)$ & 1.0 & 301 & $21.9(66)$ & 1.0 \\
\hline \multicolumn{7}{|l|}{ Ever incarcerated } \\
\hline Yes & 136 & $65.4(89)^{*}$ & $1.9(1.1$ to 3.3$)$ & 107 & $25.7(61)^{* *}$ & 2.8 (1.3 to 6.2$)$ \\
\hline No & 93 & $49.5(46)$ & 1.0 & 73 & $11.0(8)$ & 1.0 \\
\hline \multicolumn{7}{|c|}{ Previous gonorrhoea infection } \\
\hline Yes & 26 & $92.3(24)^{* * \star}$ & $10.1(2.3$ to 44.1$)$ & 28 & $42.9(12)^{\star *}$ & $3.1(1.4$ to 6.8$)$ \\
\hline No & 203 & $54.2(110)$ & 1.0 & 284 & $19.7(56)$ & 1.0 \\
\hline \multicolumn{7}{|c|}{ Previous chlamydia infection } \\
\hline Yes & 30 & $66.7(20)$ & $1.5(0.7$ to 3.4$)$ & 21 & $52.4(11)^{\star *}$ & $1.2(0.8$ to 1.9$)$ \\
\hline No & 199 & $57.3(114)$ & 1.0 & 289 & $19.4(56)$ & 1.0 \\
\hline \multicolumn{7}{|c|}{ Previous syphilis infection } \\
\hline Yes & 9 & $100(9)^{\star *}$ & - & 2 & $50.0(1)$ & $3.6(0.2$ to 58.8$)$ \\
\hline No & 220 & $56.8(125)$ & & 310 & $21.6(67)$ & 1.0 \\
\hline \multicolumn{7}{|l|}{ Current HIV infection } \\
\hline Yes & 15 & $93.3(14)^{* *}$ & $10.9(1.4$ to 84.2$)$ & 9 & $77.8(7)^{\star \star \star}$ & $13.7(2.8$ to 67.4$)$ \\
\hline No & 215 & $56.3(121)$ & 1.0 & 304 & $20.4(62)$ & 1.0 \\
\hline \multicolumn{7}{|c|}{ Sex partner ever injected drugs } \\
\hline Yes & 76 & $42.1(32)^{\star *}$ & $0.4(0.2$ to 0.7$)$ & 77 & $23.4(18)$ & $1.0(0.5$ to 1.9$)$ \\
\hline No & 125 & $64.0(80)$ & 1.0 & 183 & 23.0 (42) & 1.0 \\
\hline \multicolumn{7}{|l|}{ Daily use of pot } \\
\hline Yes & 29 & $34.5(10)^{* *}$ & $0.3(0.1$ to 0.7$)$ & 46 & $15.2(7)$ & $0.6(0.3$ to 1.4$)$ \\
\hline No & 194 & $62.1(121)$ & 1.0 & 262 & $22.9(60)$ & 1.0 \\
\hline Daily use of heroin c & togeth & & & & & \\
\hline Yes & 38 & $76.3(29)^{*}$ & $2.6(1.1$ to 5.7$)$ & 39 & $28.2(11)$ & 1.5 (0.7 to 3.2$)$ \\
\hline No & 190 & $55.8(106)$ & 1.0 & 271 & $21.0(57)$ & 1.0 \\
\hline Daily heroin use & & & & & & \\
\hline Yes & 165 & $63.0(104)^{*}$ & $1.8(1.0$ to 3.3$)$ & 232 & $22.0(51)$ & $0.8(0.5$ to 1.8$)$ \\
\hline No & 64 & $48.4(31)$ & 1.0 & 79 & $22.8(18)$ & 1.0 \\
\hline Years since debut of & usetł & & & & & \\
\hline Among positives & - & $4(3-7)^{*}$ & 1.1 (1.0 to 1.2$)$ & - & 5 (3 to 8$)$ & 1.1 (1.0 to 1.2$)$ \\
\hline Among negatives & - & $4(2-5)$ & 1.0 & - & 5 (3 to 7$)$ & 1.0 \\
\hline Has sold drugs" & & & & & & \\
\hline Yes & 49 & $83.7(41)^{\star \star *}$ & $4.6(2.1$ to 10.4$)$ & 117 & $24.8(29)$ & $1.3(0.7$ to 2.2$)$ \\
\hline No & 179 & $52.5(94)$ & 1.0 & 195 & $20.5(40)$ & 1.0 \\
\hline $\begin{array}{l}*<0.05^{* *}<0.011^{* * *} \\
\text { †Only those variable } \\
\text { tExcept for continuo } \\
\text { \$Denominator may } \\
\text { - In the previous } 6 \mathrm{~m} \\
\text { t†p value calculated } \\
\text { t\#OR expresses the }\end{array}$ & $\begin{array}{l}\text { signific } \\
\text { which } \\
\text { lumn t }\end{array}$ & $\begin{array}{l}<0.05 \text { ) for one } \\
\text { xpressed as medi } \\
\text { wing to missing }\end{array}$ & $\begin{array}{l}\text { of the sexes are sho } \\
\text { interquartile range } \\
\text { fusals to answer spe } \\
\text { les and by Mann- }\end{array}$ & $\begin{array}{l}g \text { pos } \\
\text { juesti }\end{array}$ & $\begin{array}{l}\text { and negatives. } \\
\text { skip patterns. } \\
\text { ole statistic for co }\end{array}$ & us variables. \\
\hline
\end{tabular}

3 months, including "one night stands" but not sex trade clients. Sex trade referred to any instance whereby the participants had received money or drugs in exchange for sex. The frequency of many of the sexual and drug use behaviours was measured on a six point scale from "never in the last 6 months" to "every day." Self reported STIs were assessed by asking the participants if they had ever been told by a health professional that they had gonorrhoea, syphilis, chlamydia, or genital herpes.

\section{Statistical analyses}

All analyses were stratified by sex because of significant differences in HSV-2 and syphilis seroprevalence between the sexes and the potential for effect modification of behavioural effects on STI seroprevalence by sex. The infection seroprevalence was defined as the proportion of subjects with positive tests at their baseline visit. A 95\% binomial confidence interval (CI) was calculated for each seroprevalence. Sex specific sociodemographic, behaviour, and 
seroprevalence data were compared using descriptive statistics ( $\chi^{2}$ statistics, Mann-Whitney tests or Fisher's exact tests, if cell numbers were less than 10).

For HSV-2 and syphilis separately, sex specific correlates were identified using descriptive statistics to analyse the distribution of variables (demographics, sexual behaviours, drug use behaviours) between those infected and those not infected. Sex specific syphilis analyses were not conducted for males as only one male tested positive for syphilis.

Multivariate logistic regression analyses were conducted to identify significant independent effects of demographics and behaviour variables on HSV-2, stratified by sex, and for syphilis, among females only. Any variable associated with the outcome at a significance level of 0.10 in univariate analyses was entered into logistic regression models. Potential confounders such as age and race were included in all regression models. If no meaningful changes were noted in the coefficients or the overall model, these variables were not included. Adjusted estimates of the odds ratios (AOR) and 95\% CIs were obtained. All analyses were performed using Stata Version 7.0 (Stata Corp, College Station, TX, USA).

\section{RESULTS}

The sample's sociodemographic characteristics, drug use patterns, and sexual behaviours are displayed in table 1. Of 543 participants recruited, $42.4 \%$ were female and the median age of the population was 24 years (interquartile range (IQR): $21-28$ years). Of the total population, $72.9 \%$ were IDUs. The drug of choice among this cohort was heroin, while lower proportions reported the use of marijuana, crack, and cocaine.

Males reported a significantly higher number of lifetime sexual partners than females $(p<0.0001)$. In the 6 months before study entry, females were significantly more likely than males to report trading sex for money or drugs $(\mathrm{p}<0.001)$, and having a steady partner who snorted heroin $(p<0.001)$, smoked crack $(p<0.001)$, and ever injected drugs $(p<0.03)$. Females also reported higher levels of HIV and all self reported STIs.

\section{Herpes simplex type 2}

Of the 543 participants, $37.6 \%(\mathrm{n}=204 ; 95 \%$ CI: 33.5 to 41.8$)$ tested positive for HSV-2 and only $1.3 \%(n=7)$ of the population had been previously diagnosed with herpes. HSV-2 seroprevalence was significantly higher among females than males $(58.7 \%$ versus $22.0 \%$, respectively, $\mathrm{p}<0.001$ ).

The results of univariate analyses of HSV-2 seroprevalence, stratified by sex, are shown in table 2. Older age, AfricanAmerican race, being incarcerated, over 30 lifetime partners of the opposite sex, current HIV infection, and previous self reported gonorrhoea infection were associated with HSV-2 association for both sexes. There were no significant differences in the proportion of HSV-2 seroreactivity between IDUs and NIDUs

For males, an additional significant correlate of HSV-2 infection was a previous self reported chlamydia infection. Additional significant univariate correlates for females included trading sex, lacking regular employment, having sold drugs, and self reporting of a previous syphilis infection. A number of drug use variables were positively associated with infections among females including daily heroin use and daily use of heroin and cocaine together. Use of marijuana and having a sex partner who was an IDU in the previous 6 months were inversely associated with HSV-2 infection among females.

Table 3 displays the results from sex specific multivariate logistic regression models of HSV-2 seroprevalence. Significant independent variables for HSV-2 infection among females were older age, African-American race, trading sex and daily heroin use. Among males, older age, AfricanAmerican race, testing HIV positive, ever being incarcerated and more than 30 lifetime female sex partners were independently associated with HSV-2 infection.

\section{Syphilis}

Of the 543 participants, $2.0 \%(\mathrm{n}=11 ; 95 \%$ CI $1.0 \%$ to $3.6 \%)$ tested positive for syphilis using both RPR and TPHA. Syphilis seroreactivity was $4.3 \%(\mathrm{n}=10)$ among females and $0.3 \%(\mathrm{n}=1)$ among males $(\mathrm{p}<0.001)$. Of the 10 female seroreactors, $90 \%$ were African-Americans and $80 \%$ also tested positive for HSV-2. In total, 27\% (3/11) of the seroreactors reported being previously diagnosed and treated for syphilis, however only one reported diagnoses in the previous 6 months. There was no significant difference in the proportion of syphilis seroreactivity between IDUs and NIDUs ( $1.5 \%$ versus $3.4 \%$, respectively, $\mathrm{p}=0.2$ ).

The results of female specific univariate and multivariate syphilis analyses are shown in table 4. In univariate analyses, older age, African-American race, and a self reported previous syphilis infection were significantly associated with seroreactivity, while having a sex partner who ever injected drugs was protective. In multivariate analyses, only a previous syphilis diagnosis was associated with current syphilis seroreactivity $(\mathrm{AOR}=10.3 ; 95 \% \mathrm{CI}$ : 1.9 to 56.9$)$.

\section{DISCUSSION}

In this study of ulcerative STIs among a community based cohort of injection and non-injection drug users, we found a particularly high seroprevalence of ulcerative STIs among

Table 3 Logistic regression models for HSV-2 seroprevalence: REACH III cohort by sex

\begin{tabular}{|c|c|c|}
\hline \multirow[b]{2}{*}{ Variable } & \multirow{2}{*}{$\begin{array}{l}\text { Females }(\mathrm{n}=\mathbf{2 3 0}) \\
\text { AOR }(95 \% \mathrm{CI})\end{array}$} & \multirow{2}{*}{$\begin{array}{l}\text { Males }(n=313) \\
\text { AOR }(95 \% \mathrm{Cl})\end{array}$} \\
\hline & & \\
\hline Older age & $1.1(1.0$ to 1.2$)$ & $1.1(1.0$ to 1.2$)$ \\
\hline African-American & $6.0(2.8$ to 12.7$)$ & $2.6(1.4$ to 4.8$)$ \\
\hline Sex trade $†$ & $3.2(1.2$ to 8.6$)$ & $-\ddagger$ \\
\hline Daily use of heroin $†$ & $3.6(1.6$ to 7.7$)$ & $-\ddagger$ \\
\hline \multicolumn{3}{|c|}{ Lifetime opposite sex partners } \\
\hline$<10$ & 1.0 & 1.0 \\
\hline $10-30$ & $1.3(0.6$ to 2.7$)$ & $1.6(0.7$ to 3.9$)$ \\
\hline$>30$ & $1.8(0.6$ to 5.5$)$ & $2.6(1.1$ to 6.1$)$ \\
\hline Current HIV infection & $-\ddagger$ & $11.1(1.8$ to 67.5$)$ \\
\hline Ever been incarcerated & $-\ddagger$ & $2.7(1.1$ to 6.6$)$ \\
\hline
\end{tabular}

AOR, adjusted odds ratios; $95 \% \mathrm{Cl}, 95 \%$ confidence intervals. †ln the previous 6 months. $\ddagger$ Variables were not included in final regression model as they were not significant in either univariate or multivariate analyses. 
Table 4 Statistically significant correlates for syphilis seroreactivity of females $(n=230)$ from the REACH III cohort†

\begin{tabular}{|c|c|c|c|c|}
\hline & Total no & $\begin{array}{l}\text { Positiveł§ } \\
\% \text { (n) }\end{array}$ & $\begin{array}{l}\text { Odds ratio (OR) } \\
(95 \% \mathrm{Cl})\end{array}$ & $\begin{array}{l}\text { Adjusted OR } \\
(95 \% \mathrm{Cl})\end{array}$ \\
\hline \multicolumn{5}{|l|}{ Median age } \\
\hline Among positives & - & $28(27-28)^{*}$ & $1.3(1.0$ to 1.7$)+\dagger$ & $1.3(0.96$ to 1.6$)+\dagger$ \\
\hline Among negatives & - & $25(21-28)$ & & \\
\hline \multicolumn{5}{|l|}{ African-American } \\
\hline Yes & 111 & $8.1(9)^{* *}$ & $10.3(1.3$ to 82.9$)$ & $3.9(0.4$ to 35.9$)$ \\
\hline No & 118 & $0.9(1)$ & 1.0 & 1.0 \\
\hline \multicolumn{5}{|c|}{ Self reported previous syphilis Infection } \\
\hline Yes & 9 & $33.3(2)^{\star *}$ & 15.2 (3.1 to 73.7$)$ & 10.3 (1.9 to 56.9$)$ \\
\hline No & 220 & $3.2(8)$ & 1.0 & 1.0 \\
\hline \multicolumn{5}{|c|}{ Sex partner ever injected drugs } \\
\hline Yes & 76 & $0^{*}$ & 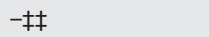 & -暑 \\
\hline No & 125 & $6.4(8)$ & & \\
\hline \multicolumn{5}{|c|}{ 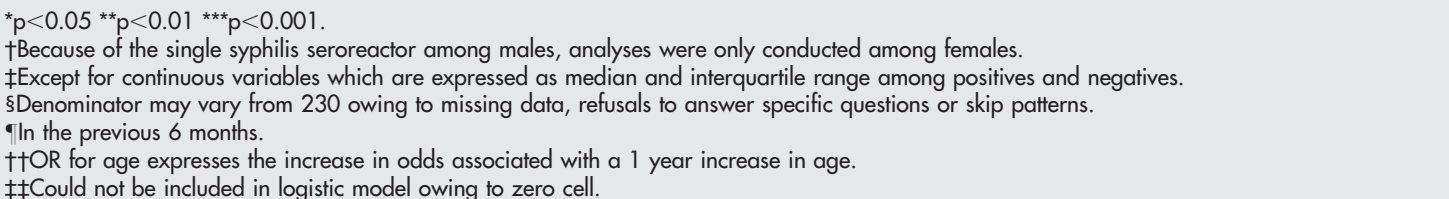 } \\
\hline
\end{tabular}

female drug users, especially African-American females; however few participants had been previously diagnosed with these infections. In addition, there were no significant differences in HSV-2 or syphilis seroprevalence between IDUs and NIDUs.

The HSV-2 and syphilis seroprevalence data among female drug users in our study ( $58.7 \%$ and $4.3 \%$, respectively) were higher than those reported for the general population. HSV-2 seroprevalence was reported to be $25.6 \%$ among females in the 1988-94 National Health and Nutrition Examination Survey III (NHANES) ${ }^{13}$ and $24.6 \%$ among females aged $18-30$ at health clinics in Pittsburgh. ${ }^{14}$ Syphilis seroreactivity among females was measured at $0.8 \%$ in the NHANES-III. ${ }^{15}$ In contrast, our male HSV-2 seroprevalence $(22 \%)$ was more similar to that of $17.8 \%$ determined among males in the NHANES-III survey. ${ }^{13}$ It is important to note that the seroprevalence data from this research may not be generalisable to other cities because of the relatively high STI rates in Baltimore. ${ }^{16}$ However, the HSV-2 and syphilis data reported in this study were very similar to those reported from national inner city STD clinics and drug treatment populations of the same age..$^{17} 18$

The low proportion of people reporting previous diagnoses with these STIs, especially HSV-2, is alarming yet not surprising. Previous HSV-2 research in the general population has demonstrated that the majority of seropositive people were unaware of their infection status as a result of unrecognised or atypical infections. ${ }^{13} 1920$ Drug users have been shown to have low healthcare utilisation, ${ }^{21}$ and therefore will not likely seek screening for these infections, other than when it is required-for example, routine syphilis screening at correctional institutes in Maryland. This lack of awareness of infection status also suggests that few individuals are taking appropriate measures to treat, control, or prevent transmission of their infections. These factors combined with the high proportion of infected females and the high number of sex partners create the potential for high transmission of infection, and demonstrate the importance for screening programmes and prevention programmes which include education on symptom recognition.

The increased seroprevalence of ulcerative STIs among females, African-Americans and older aged participants is common in STI literature. ${ }^{14} 151922-25$ Correlates identified for HSV-2 infection among males were related to high risk sexual behaviours; independent correlates of infection included an increased number of lifetime female sex partners and current HIV infection. For females, both high risk sex and drug use behaviours were identified as correlates of HSV-2 infection. In multivariate analyses, after controlling for age and race, only trading sex for drugs or money and daily heroin use were identified as independent correlates of infection. Interestingly, in univariate analyses of females, having a sex partner who was an IDU was associated with lower HSV-2 and syphilis seroprevalence; this may be explained in part by the lower proportion of AfricanAmericans who have IDUs as sexual partners and, as discussed above, African-American race is associated with seroreactivity.

This study supports previous literature describing the overlap between sexual relationships and drug use among female drug users, ${ }^{8} 926$ which, as in the current study, has previously been attributed to the higher proportion of females than males who exchanged sex for drugs or money and had drug using sex partners. This difference speaks to the importance of developing interventions for women which focus on the root causes, such as drug addiction and economic dependence on men, that influence transactional sex.

This study was subject to several limitations. The identification of correlates for syphilis seroreactivity was severely limited by the low seroprevalence. The syphilis serology itself is a limitation as the difficulty in interpreting the meaning of positive syphilis serology (that is, new versus treated infections) may have been exacerbated by the high prevalence of injection drug use which can result in false positive RPR results. The cross sectional study design, the use of serological assays, and the limitation of many behavioural questions to the previous 6 months did not allow the determination of causal relations between behaviours and STI acquisition. However, this bias may have been reduced by the young age of this population as infections may have been identified relatively soon after acquisition (for example, syphilis is commonly acquired in the 20 s or early $30 \mathrm{~s}^{28}$ ). The self reported behavioural variables are subject to social desirability biases; however, it is hoped that extensive training of interviewers reduced these biases. In addition, baseline questionnaires did not collect information on sexual network and mixing patterns, which may be extremely informative in explaining the high seroprevalence of infection among African-Americans compared to white people.

This study has attempted to provide a more accurate estimate of STI seroprevalence among young urban drug users than previous studies by using a community recruited cohort and including both IDUs and NIDUs. The study 


\section{Key messages}

- The seroprevalence of HSV-2 and syphilis is high (58.7\% and $4.3 \%$, respectively) among young female drug users in Baltimore City

- Few infected participants knew of their infection status, indicating that STI screening and education programmes should be implemented as a part of outreach services to young drug users

- Injection and non-injection drug users had similar seroprevalence of infection and therefore harm reduction programmes for all drug users should focus on safe sex messages

population demonstrated a high level of sexual risk and a high seroprevalence of HSV-2 and syphilis, especially among female participants, which places all of the population at high risk for the sexual transmission of infections, including HIV. Although the majority of previous research among drug users has focused on injection risk behaviours of IDUs for disease prevention, this study indicates that the sexual behaviours of both IDUs and NIDUs are of public health importance. Intervention and outreach programmes for young drug users should offer STI testing, education on the identification of STIs, and promote safe sex messages in order to prevent the further transmission of all STIs.

\section{ACKNOWLEDGEMENTS}

The authors would like to acknowledge funding for this study from the National Institute on Drug Abuse (DAl1880), the REACH staff for their effort in the conduct of this study and the REACH participants for their time and commitment. We would like to thank Shirley McCullough for the preparation and testing of serum samples and Marcella Sapun for her help with data management. In addition, we would like to acknowledge the partial funding for this research by the Summer Epidemiology Fund from the Department of Epidemiology, Johns Hopkins Bloomberg School of Public Health, Baltimore, Maryland. SSP was supported by funding from the Alberta Heritage Foundation for Medical Research.

\section{CONTRIBUTORS}

SSP coordinated HSV-2 testing, performed data analysis, and prepared the manuscript; SGS contributed to the writing of manuscript, acts as principal investigator of the cohort and therefore helped with coordination of data collection and data management; SAS provided the initial idea for this research, was involved with initial coordination of cohort, and reviewed the manuscript; TET was involved with the development and review of the manuscript

\section{Authors' affiliations}

S S Plitt, S G Sherman, T E Taha, Department of Epidemiology, Johns Hopkins Bloomberg School of Public Health, Baltimore, MD, USA $S$ A Strathdee, Division of International Health and Cross Cultural Medicine, University of California, San Diego, CA, USA

\section{REFERENCES}

1 Rottingen JA, Cameron DW, Garnett GP. A systematic review of the epidemiologic interactions between classic sexually transmitted diseases and HIV: how much really is known? Sex Transm Dis 2001;28:579-97.
2 Dickerson MC, Johnston J, Delea TE, et al. The causal role for genital ulcer disease as a risk factor for transmission of human immunodeficiency virus. An application of the Bradford Hill criteria. Sex Transm Dis 1996:23:429-40.

3 Fleming DT, Wasserheit JN. From epidemiological synergy to public health policy and practice: the contribution of other sexually transmitted diseases to sexual transmission of HIV infection. Sex Transm Infect 1999;75:3-17.

4 Spinola SM, Orazi A, Arno JN, et al. Haemophilus ducreyi elicits a cutaneous infiltrate of CD4 cells during experimental human infection. J Infect Dis 1996; 173:394-402.

5 Schacker T, Ryncarz AJ, Goddard J, et al. Frequent recovery of HIV-1 from genital herpes simplex virus lesions in HIV-1-infected men. JAMA 1998;280:61-6.

6 Cohen E, Navaline H, Metzger D. High-risk behaviors for HIV: a comparison between crack-abusing and opioid-abusing African-American women. J Psychoactive Drugs 1994;26:233-41.

7 Kim MY, Marmor M, Dubin N, et al. HIV risk-related sexual behaviors among heterosexuals in New York City: associations with race, sex, and intravenous drug use. AIDS 1993;7:409-14.

8 Henderson DJ, Boyd C, Mieczkowski T. Gender, relationships, and crack cocaine: a content analysis. Res Nurs Health 1994;17:265-72.

9 Powis B, Griffiths P, Gossop M, et al. The differences between male and female drug users: community samples of heroin and cocaine users compared. Subst Use Misuse 1996:31:529-43.

10 Carlson RG, Wang J, Siegal HA, et al. An ethnographic approach to targeted sampling: problems and solutions in AIDS prevention research among injection drug and crack-cocaine users. Human Organization 1994;53:279-86

11 Fuller CM, Vlahov D, Ompad DC, et al. High-risk behaviors associated with transition from illicit non-injection to injection drug use among adolescent and young adult drug users: a case-control study. Drug Alcohol Depend 2002:66:189-98.

12 Larsen SA, Steiner BM, Rudolph AH. Laboratory diagnosis and interpretation of tests for syphilis. Clin Microbiol Rev 1995;8:1-21.

13 Fleming DT, McQuillan GM, Johnson RE, et al. Herpes simplex virus type 2 in the United States, 1976 to 1994. N Engl J Med 1997;337:1105-11.

14 Cherpes TL, Meyn LA, Krohn MA, et al. Risk factors for infection with herpes simplex virus type 2: role of smoking, douching, uncircumcised males, and vaginal flora. Sex Transm Dis 2003;30:405-10.

15 Hahn RA, Magder LS, Aral SO, et al. Race and the prevalence of syphilis seroreactivity in the United States population: a national sero-epidemiologic study. Am J Public Health 1989;79:467-70.

16 Centers for Disease Control. Primary and secondary syphilis-United States, 2000-2001. MMWR Morb Mortal Wkly Rep 2002:51:971-3.

17 Gottlieb SL, Douglas JM Jr, Schmid DS, et al. Seroprevalence and correlates of herpes simplex virus type 2 infection in five sexually transmitted-disease clinics. J Infect Dis 2002;186:1381-9.

18 Finelli L, Farley TP, Gibson JJ, et al. Prevalence monitoring in syphilis surveillance: results from a multicenter research program. Sex Transm Dis 2002;29:769-774.

19 Stanberry L, Cunningham A, Mertz G, et al. New developments in the epidemiology, natural history and management of genital herpes. Antiviral Res 1999;42:1-14.

20 Musher DM. Chapter 35: Early syphilis. In: Holmes KK, Sparling PF, Mardh P-A, Lemon SM, Stamm WE, Piot P, et al, eds. Sexually transmitted diseases. 3rd ed. New York: McGraw-Hill, 1999:479-85.

21 McCoy CB, Metsch LR, Chitwood DD, et al. Drug use and barriers to use of health care services. Subst Use Misuse 2001;36:789-806.

22 Lopez-Zetina J, Ford W, Weber $M$, et al. Predictors of syphilis seroreactivity and prevalence of HIV among street recruited injection drug users in Los Angeles County, 1994-6. Sex Transm Infect 2000;76:462-9.

23 Williams ML, Elwood WN, Weatherby NL, et al. An assessment of the risks of syphilis and HIV infection among a sample of not-in-treatment drug users in Houston, Texas. AIDS Care 1996:8:671-82.

24 Ross MW, Hwang LY, Leonard L, et al. Sexual behaviour, STDs and drug use in a crack house population. Int J STD AIDS 1999;10:224-30.

25 Hwang LY, Ross MW, Zack C, et al. Prevalence of sexually transmitted infections and associated risk factors among populations of drug abusers. Clin Infect Dis 2000;31:920-6.

26 Bruneau J, Lamothe F, Soto J, et al. Sex-specific determinants of HIV infection among injection drug users in Montreal. CMAJ 2001;164:767-73.

27 Evans JL, Hahn JA, Page-Shafer K, et al. Gender differences in sexual and injection risk behavior among active young injection drug users in San Francisco (the UFO Study). J Urban Health 2003;80:137-46.

28 Stamm LV. Chapter 33: Biology of Treponema pallidum. In: Holmes KK, Sparling PF, Mardh PA, Lemon SM, Stamm WE, Piot P, et al, eds. Sexually transmitted diseases. New York: McGraw-Hill, 1999. 